\title{
Differential Involvement of NMDA and AMPA Receptors Within the Nucleus Accumbens in Consolidation of Information Necessary for Place Navigation and Guidance Strategy of Mice
}

\author{
Francesca Sargolini, ${ }^{1,2}$ Cédrick Florian, ${ }^{1}$ Alberto Oliverio, ${ }^{2}$ Andrea Mele, ${ }^{2}$ \\ and Pascal Roullet ${ }^{1,3}$ \\ ${ }^{1}$ Centre de Recherches sur la Cognition Animale (CRCA), Université Paul Sabatier, CNRS-UMR (ex FRE 2382), Toulouse, France; \\ ${ }^{2}$ Dipartimento di Genetica e Biologia Molecolare, Università di Roma 'La Sapienza,' P.le Aldo Moro, 5, 00185, Roma, Italia
}

\begin{abstract}
Recent evidence now points to a role of glutamate transmission within the nucleus accumbens (Nacc) in spatial learning and memory. Unfortunately, the role of the distinct classes of glutamate receptors within this structure in mediating the different steps of the memorization process is not clear. The aim of this study therefore was to further investigate this issue, trying to assess the involvement of the two classes of glutamate receptors within the Nacc in consolidation of spatial information using an associative spatial task, the water maze. For this purpose, focal injections of the NMDA antagonist, AP-5, and of the AMPA antagonist, DNQX, have been performed immediately after the training phase, and mice have been tested for retention $24 \mathrm{~h}$ later. Two different versions of the water-maze task have been used: In the place version, animals could learn the position of the platform using visual distal cues, and in the cue version, the location of the platform was indicated by a single proximal cue. The results demonstrated that posttraining NMDA receptor blockade affects mice response in the place but not in the cue water-maze task. On the contrary, AMPA receptor blockade induced no effect in either version of the task. These data confirm a functional dissociation between glutamate receptors located in the Nacc in modulating spatial memory consolidation and indicate that they are specifically involved in consolidation of information necessary to acquire a place but not to a guidance strategy.
\end{abstract}

The investigation of the neuroanatomical bases of spatial cognition in mice has received growing attention over the last $10 \mathrm{yr}$. Although the hippocampus is generally considered to play a central role in the processing of space, evidence has accumulated that several other nervous structures participate in such processes. In particular, the nucleus accumbens (Nacc) is strongly connected to brain regions, such as the hippocampus or the prefrontal cortex (Kelley and Domesick 1982; Groenewegen et al. 1987), involved in spatial information processing (Schacter et al. 1989; Sargolini et al. 1999). The possible role of this structure in spatial learning has been sustained by behavioral studies showing that temporary or permanent inactivation of Nacc impairs performance in spatial learning tasks (Annett et al. 1989; Ploeger et al. 1994; Seamans and Phillips 1994).

Nacc inputs are mainly glutamatergic, and a high density of NMDA and AMPA receptors has been reported within this structure (Albin et al. 1991). Thus, intact transmission from cortical and allocortical brain areas seems to be essential for correct processing of spatial information (Floresco et al. 1997; Sargolini et al. 1999). Along this line, it has been demonstrated that blockade of both classes of glutamate receptors within the Nacc impaired performance in different spatial learning tasks (MaldonadoIrizarry and Kelley 1995; Usiello et al. 1998). However, in these studies pretraining pharmacological manipulations have been used; therefore, it is difficult to dissociate the effects on the dif-

\footnotetext{
${ }^{3}$ Corresponding author.

E-MAIL roullet@cict.fr; FAX (33) 5-61-55-61-54.

Article and publication are at http://www.learnmem.org/cgi/doi/10.1101/ Im.54003.
}

ferent phases of information processing. Posttraining administrations, on the contrary, are thought to act on memory consolidation, while sparing acquisition and recall processes (McGaugh 1966; Gold and McGaugh 1975). In a recent study, we have shown that NMDA receptor blockade immediately after the training phase affected mice response $24 \mathrm{~h}$ later in a nonassociative spatial task, in which mice are required to discriminate a spatial rearrangement of the configuration of a set of five objects (Roullet et al. 2001). On the contrary, AMPA receptor blockade had no effects (Roullet et al. 2001). These results demonstrate that the Nacc is involved in the consolidation of spatial information and point to a functional dissociation between NMDA and AMPA receptors located in this structure in mediating spatial memory consolidation.

The aim of this study was to investigate the involvement of Nacc, and more specifically of the different glutamate receptors within this structure, in the consolidation of spatial information in an associative spatial task, designed to estimate the ability of mice to locate a submerged platform in a pool using visual cues. For that purpose, we used a modified version of the Morris watermaze task, composed of a massed training of four consecutive sessions and a probe test $24 \mathrm{~h}$ later, during which the platform was removed. The effects of posttraining focal administrations of AMPA and NMDA receptor antagonists into the Nacc have been compared in two different versions of the water-maze task. In the spatial version, a submerged platform remained in a fixed position across trials, and several distal cues were attached to the walls surrounding the pool. In the cue version, a unique salient cue was suspended above the submerged platform, and the plat- 
A

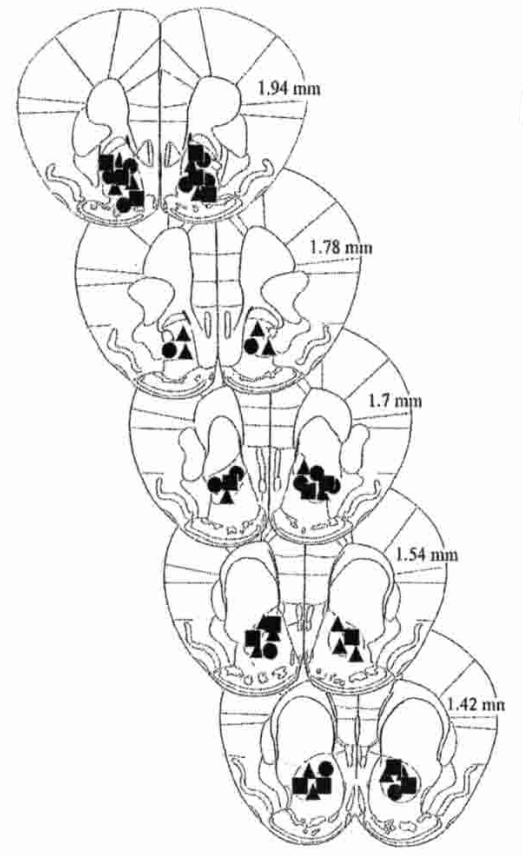

B

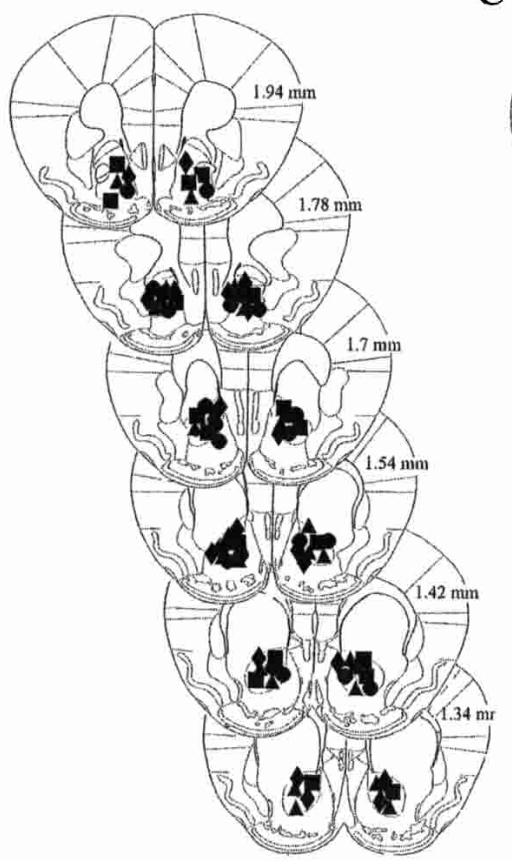

C

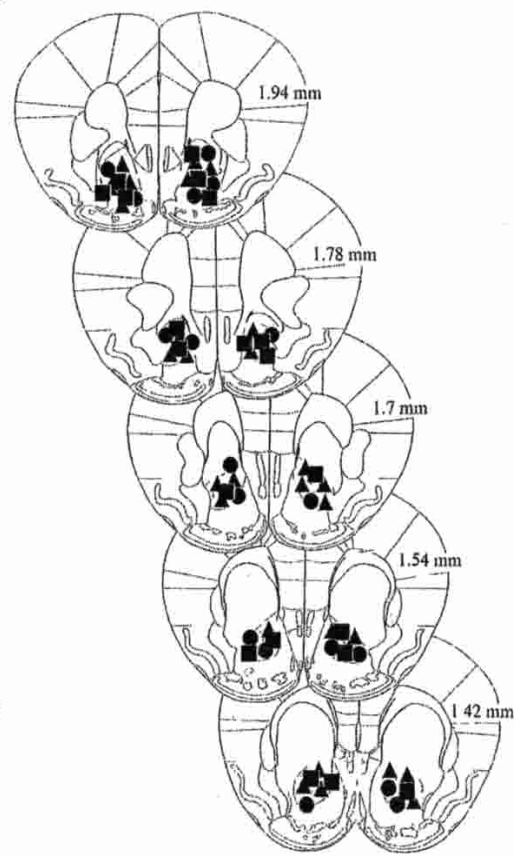

Figure 1 Schematic representation of cannula placements in all experiments. Each symbol represents the site of injection for one animal. ( $A$ ) Experiment 1, posttraining AP-5 injections in the place water-maze task. (A) Saline; $(\mathbf{\square}) 0.10 \mu \mathrm{g} / \mathrm{side}$ AP-5; ( $)$ 0.15 $\mu$ g/side AP-5. (B) Experiment 2,

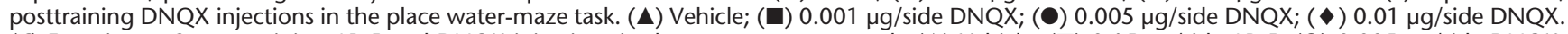

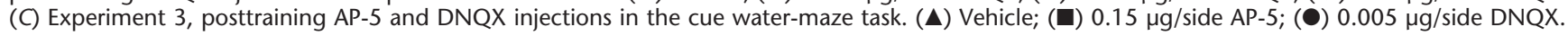

form as well as the cue changed position across the four training sessions; during the probe test trial, the platform was removed and the salient cue was positioned in a new quadrant. In both versions, the platform is invisible during learning sessions, thus involving a similar motivational state. The only difference between the two tasks is based on the cues that animals could use to find the platform. In one case (place version), mice have to perform a place response, which is guided by a spatial representation of the environment. In the other case (cue version), mice are required to approach the platform by associating it with the unique visual cue. These experiments allow us to compare the possible involvement of glutamate receptors within the Nacc in consolidating information necessary for place and guidance strategy.

\section{RESULTS}

\section{Cannula Placements Verification}

Figure 1 shows a schematic representation of cannula placements for all the experiments. The injection sites were located in the Nacc core for the majority of mice. Only animals showing a correct cannula placement were included in the statistical analysis. A total of 35 animals (Experiment 1: 10 mice; Experiment 2: 16 mice; Experiment 3: 9 mice) were excluded because of incorrect Nacc placements.

\section{Training Phase}

Table 1 shows the absolute values for session latencies to escape onto the platform during training phase on day 1 , in all three

Table 1. Session Latencies (Seconds) to Escape Onto the Platform During Training Phase, and Swimming Speed (Centimeters/Second) and Time Spent in the Periphery of the Pool (Seconds) During Probe Test, in the Three Experiments

\begin{tabular}{|c|c|c|c|c|c|c|c|}
\hline \multirow[b]{2}{*}{ Experiment } & \multirow[b]{2}{*}{ Groups $(N)$} & \multicolumn{4}{|c|}{ Training } & \multicolumn{2}{|c|}{ Probe test } \\
\hline & & S1 & S2 & S3 & S4 & Speed & T periphery \\
\hline \multirow[t]{3}{*}{1} & Control (11) & $97.82 \pm 13.06$ & $56.27 \pm 7.30$ & $50.73 \pm 13.80$ & $39.82 \pm 5.12$ & $22.44 \pm 0.47$ & $16.45 \pm 2.36$ \\
\hline & AP-5 $0.10(8)$ & $102.75 \pm 18.62$ & $67.00 \pm 8.70$ & $52.00 \pm 10.70$ & $39.50 \pm 13.19$ & $21.88 \pm 1.60$ & $16.60 \pm 1.71$ \\
\hline & AP-5 $0.15(8)$ & $98.75 \pm 13.21$ & $74.37 \pm 17.96$ & $38.87 \pm 6.78$ & $53.75 \pm 15.38$ & $23.34 \pm 1.43$ & $16.35 \pm 2.05$ \\
\hline \multirow[t]{4}{*}{2} & Control (11) & $93.82 \pm 10.00$ & $64.91 \pm 13.21$ & $50.00 \pm 6.82$ & $44.36 \pm 7.63$ & $23.76 \pm 1.43$ & $19.51 \pm 1.78$ \\
\hline & DNQX $0.001(10)$ & $80.60 \pm 9.80$ & $64.50 \pm 6.94$ & $48.00 \pm 5.57$ & $42.60 \pm 8.77$ & $21.08 \pm 1.79$ & $19.00 \pm 2.03$ \\
\hline & DNQX 0.005 (11) & $88.90 \pm 11.11$ & $72.90 \pm 14.89$ & $37.60 \pm 5.70$ & $46.60 \pm 6.62$ & $22.30 \pm 2.10$ & $18.10 \pm 2.24$ \\
\hline & DNQX $0.010(10)$ & $84.50 \pm 9.49$ & $55.60 \pm 7.12$ & $36.40 \pm 5.31$ & $35.40 \pm 6.17$ & $22.70 \pm 1.00$ & $18.20 \pm 2.21$ \\
\hline \multirow[t]{3}{*}{3} & Control (14) & $68.79 \pm 9.37$ & $46.07 \pm 3.96$ & $38.50 \pm 4.89$ & $40.86 \pm 6.53$ & $23.29 \pm 0.83$ & $11.15 \pm 1.36$ \\
\hline & AP-5 $0.15(9)$ & $71.22 \pm 8.51$ & $45.67 \pm 7.40$ & $37.33 \pm 8.62$ & $32.55 \pm 6.65$ & $23.89 \pm 1.42$ & $13.31 \pm 1$. \\
\hline & DNQX $0.005(10)$ & $74.20 \pm 15.75$ & $58.00 \pm 7.64$ & $47.40 \pm 6.84$ & $35.70 \pm 6.47$ & $21.99 \pm 0.98$ & $13.48 \pm 2.22$ \\
\hline
\end{tabular}

Data represent mean \pm SEM. 


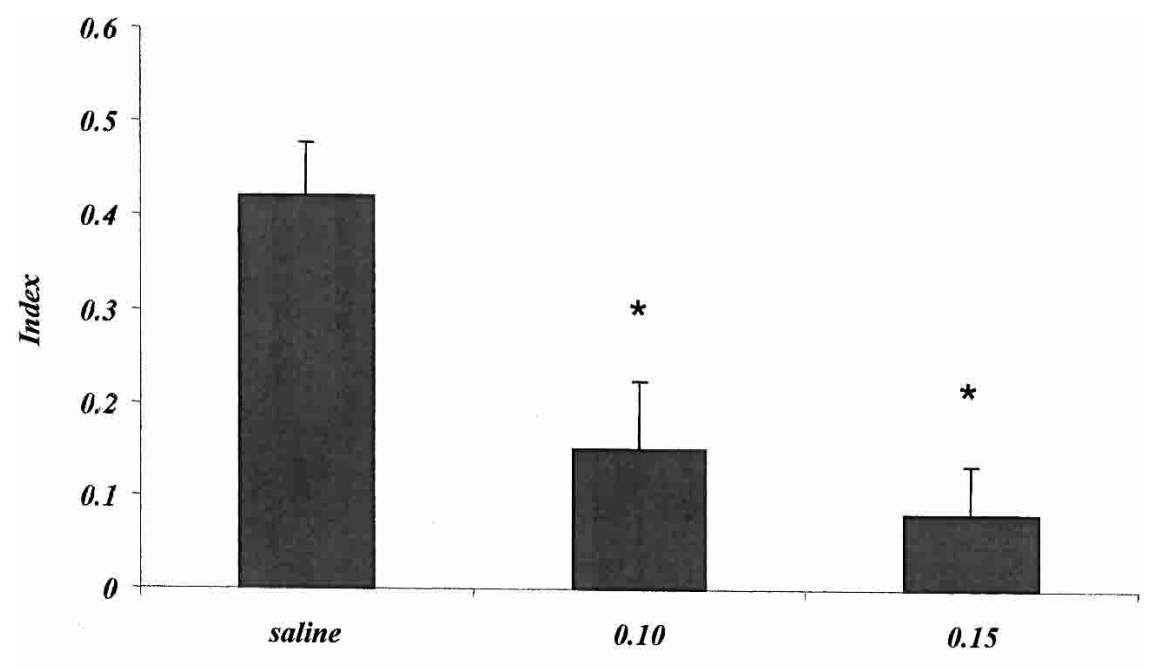

AP-5 ( $\mu \mathrm{g} /$ side $)$

Figure 2 Experiment 1, effect of posttraining saline and AP-5 administrations on the place watermaze task. The histogram represents the index \pm SEM, calculated as difference between the number of crossings of the annulus surrounding the expected position of the platform and the mean number of crossings of the three remaining annuli, divided by the total number of annulus crossings, during the probe test. $\left(^{*}\right) p<0.05$, saline versus AP-5 groups.
Figure $3 \mathrm{~A}$ shows the time spent in the four quadrants during the probe test by saline- and AP-5-injected mice. Control animals spent more time in the correct quadrant, compared with the remaining three quadrants. Focal AP-5 injections immediately after the last training session decreased the time spent in the correct quadrant as well as the difference between time spent in the correct quadrant and the remaining three quadrants. The two-factor ANOVA showed no treatment effect $\left(F_{2,96}=0.063 ; \quad p=0.939\right), \quad$ a significant quadrants effect $\left(F_{3,96}=25.898 ; p=0.001\right)$, and a significant interaction between the two factors $\left(F_{6,96}=6.936 ; p=0.001\right)$. Post hoc comparison showed a significant difference between the correct quadrant and the other three quadrants for control animals but not for AP-5-treated mice. For the AP-5 0.1 group, a significant difference was observed between the correct quadrant and the opposite and left quadrants but not the right quadrant. In the AP-5 0.15 group, post hoc comparison showed no significant difference among all four quadrants. experiments. All groups decreased latency to find the platform across trial blocks. The ANOVA analysis showed no treatment effect, a significant session effect, and no interaction between the two factors, in all three experiments.

\section{Experiment 1: Effects of Posttraining AP-5 Injections on Probe Test $24 \mathrm{~h}$ Later in the Place Water-Maze Task}

Table 1 shows the effects of immediately posttraining AP-5 injections on swimming speed and time spent in the periphery of the pool $(10 \mathrm{~cm}$ from the wall), during the 60 -sec probe test trial, on day 2 . No major differences have been observed between saline- and AP-5-injected mice in both parameters. The one factor ANOVA showed no treatment effect (Speed: $F_{2,24}=0.374$; $p=0.692 ; \quad \mathrm{T}$ periphery: $\quad F_{2,24}=1.861$; $p=0.177)$.

Figure 2 shows the effects of posttraining AP-5 injections on the index, calculated on the basis of annulus crossings during the probe test. The mean index of the control group is 0.42 , thus indicating that salineinjected mice crossed the annulus in the correct quadrant about four times more than the remaining three annuli. Posttraining AP-5 injections significantly decreased the number of annulus crossings in the correct quadrant. The one-factor analysis of variance showed a mean treatment effect $\left(F_{2,24}=9.203 ; p=0.001\right)$.

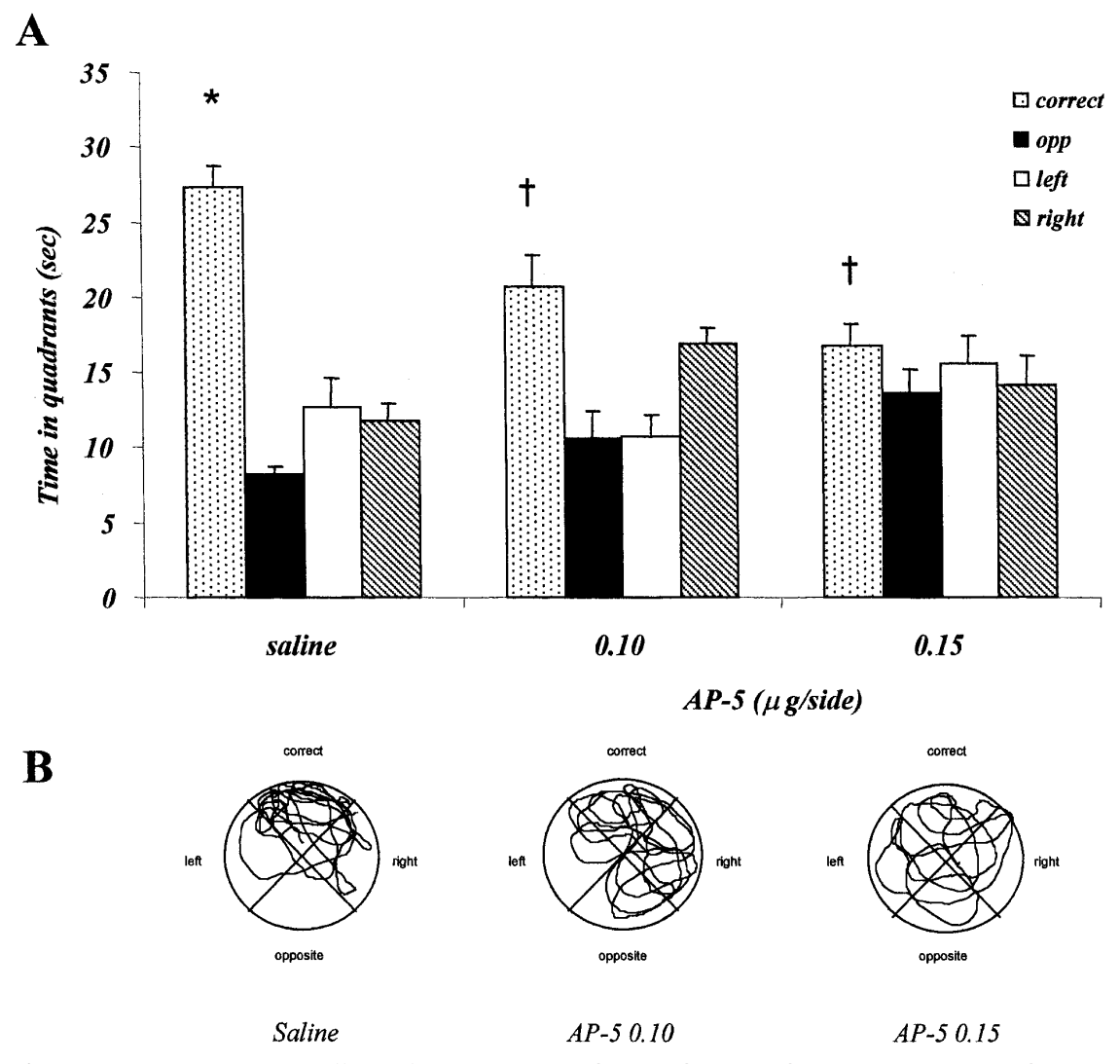

Figure 3 Experiment 1, effect of posttraining saline and AP-5 administrations on probe test performance in the place water-maze task. (A) Time spent in the four quadrants by the mice injected with saline, $0.10 \mu \mathrm{g} /$ side AP-5, and $0.15 \mu \mathrm{g} / \mathrm{side}$ AP-5. (B) Representative paths taken by animals treated with saline, $0.10 \mu \mathrm{g} /$ side AP-5, and $0.15 \mu \mathrm{g} /$ side AP-5. $\left(^{*}\right) p<0.05$, correct versus opposite, right, left quadrants within groups; $(\dagger) p<0.005$, correct quadrant saline versus AP-5 groups. 
Experiment 2: Effects of Posttraining DNQX Injections on Probe Test $24 \mathrm{~h}$ Later in the Place Water-Maze Task Table 1 shows the effects of immediately posttraining DNQX injections on swimming speed and time spent in the periphery of the pool $(10 \mathrm{~cm}$ from the wall), during the 60 -sec probe test trial, on day 2. No major differences were observed between vehicleand DNQX-injected mice in both parameters. The one-factor ANOVA showed no treatment effect (Speed: $F_{3,38}=0.441$; $p=0.725$; T periphery: $F_{3,38}=0.107 ; p=0.955$ ).

Figure 4 shows the effects of posttraining DNQX injections on the index, calculated on the basis of annulus crossings during the probe test. Both control and DNQX-treated mice crossed the annulus significantly more in the correct quadrant, compared with the remaining three quadrants. No significant difference in the spatial index among the four groups has been observed. The one-factor ANOVA showed no treatment effect $\left(F_{3,37}=0.202\right.$; $p=0.895)$.

Figure $5 \mathrm{~A}$ shows the time spent in the four quadrants during the probe test, by vehicle- and DNQX-injected mice. Control group as well as DNQX-treated mice spent more time in the correct quadrant, compared with the remaining three quadrants. No significant difference has been observed among the four groups. The two-factor ANOVA showed no treatment effect $\left(F_{3,148}=0.012 ; \quad p=0.998\right), \quad$ a significant quadrants effect $\left(F_{3,148}=78.98 ; p=0.001\right)$, but no interaction between the two factors $\left(F_{3,148}=0.928 ; p=0.502\right)$.

\section{Experiment 3: Effects of Posttraining AP-5 and DNQX Injections on Probe Test $24 \mathrm{~h}$ Later in the Cue Water-Maze Task}

Table 1 shows the effects of immediately posttraining AP-5 and DNQX injections on swimming speed and time spent in the periphery of the pool $(10 \mathrm{~cm}$ from the wall), during the 60-sec probe test trial, on day 2 . No major differences have been observed between vehicle- and AP-5- or DNQX-injected mice in both parameters. The one-factor ANOVA showed no treatment effect (Speed: $F_{2,30}=0.764 ; p=0.475 ;$ T periphery: $F_{2,30}=0.578$; $p=0.567)$.

Figure 6 shows the effects of posttraining AP- 5 and DNQX

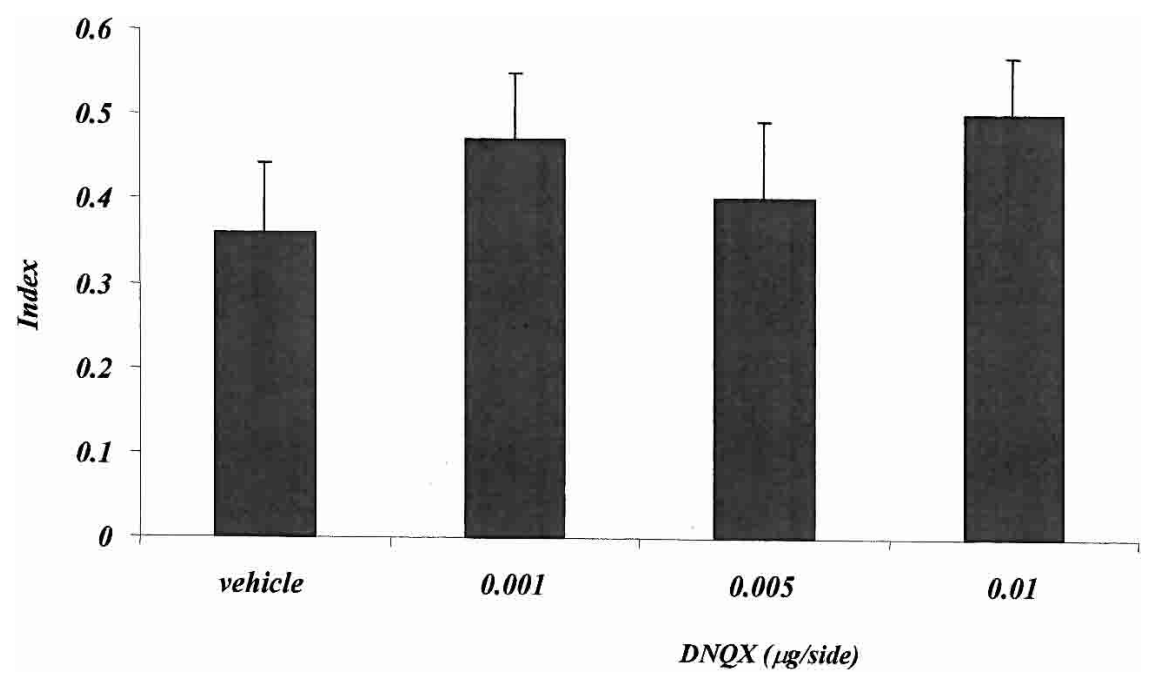

Figure 4 Experiment 2, effect of posttraining vehicle and DNQX administrations on the place water-maze task. The histogram represents the index \pm SEM, calculated as the difference between the number of crossings of the annulus surrounding the expected position of the platform and the mean number of crossings of the three remaining annuli, divided by the total number of annulus crossings, during the probe test. injections on the index, calculated on the basis of annulus crossings during the probe test. The mean index of the control group is 0.34 , thus indicating that saline-injected mice crossed the annulus in the correct quadrant about three times more than the remaining three annuli. Posttraining AP-5 and DNQX injections did not alter this response. The one-factor analysis of variance showed no treatment effect $\left(F_{2,30}=1.491 ; p=0.241\right)$.

The time spent in the four quadrants during the probe test by vehicle, AP-5, and DNQX groups is represented in Figure 7A. Vehicle as well as AP-5- and DNQX-injected mice spent significantly more time in the correct quadrant, compared with the other three quadrants. The two-factor analysis of variance showed no treatment effect $\left(F_{2,120}=0.002 ; p=0.998\right)$, a significant quadrant effect $\left(F_{3,120}=19.583 ; p=0.001\right)$, but no treatment $\times$ quadrant interaction $\left(F_{6,120}=0.472 ; p=0.828\right)$.

\section{DISCUSSION}

The aim of this study was to investigate the role of Nacc in the consolidation of spatial information, and to compare the effects of temporary inactivation of glutamate transmission within this structure in the place and the cue versions of the water-maze task. In the place version used in the present study, mice can learn the position of the platform, which is always located in the same quadrant during training sessions, using visual distal cues. The cue version of the water maze differs from the classical nonspatial water-maze task, in which animals are required to swim to a visible platform (Morris 1984). In the present cue version, the platform is invisible during the training phase and a single proximal cue indicates its location. Changing the position of the platform as well as that of the cue prevents the animals from using spatial bias. Compared with the classical nonspatial water maze, this procedure has more similarities with the place version, and for that reason seems more suitable for a direct comparison between the two tasks. The first similarity is that the platform is invisible during the training phase. Secondly, both procedures allow the performance of a probe test, in which the platform is removed and, in the cue water maze, the proximal cue is located in the quadrant opposite to the one "reinforced" during the last training session. The only difference between the two tasks is based on cues that animals could use to locate the platform. In one case (cue version), mice are required to direct themselves toward a unique salient cue, a visual beacon. In the other case (place version), animals have to create a central representation of external cues and compute the exact location of the platform using a spatial map of the environment (O'Keefe and Nadel 1978).

In both procedures, there is a progressive decrease of the latency to find the platform from S1 to S4 in control animals, thus indicating that learning has occurred. It has been suggested that animals can use different strategies to find the platform, for example, they can improve escape latency by increasing swimming speed or by learning to swim at a certain distance from the wall of the pool (Morris 1984; Lipp and Wolfer 1998; Lassalle et al. 2000). These procedural components can be revealed by analyzing probe test data. In our experiments during the probe test, vehicle-injected mice tended to swim in the quadrant where they were expected to find the platform. This indicates that mice were able to use distal cues 
A

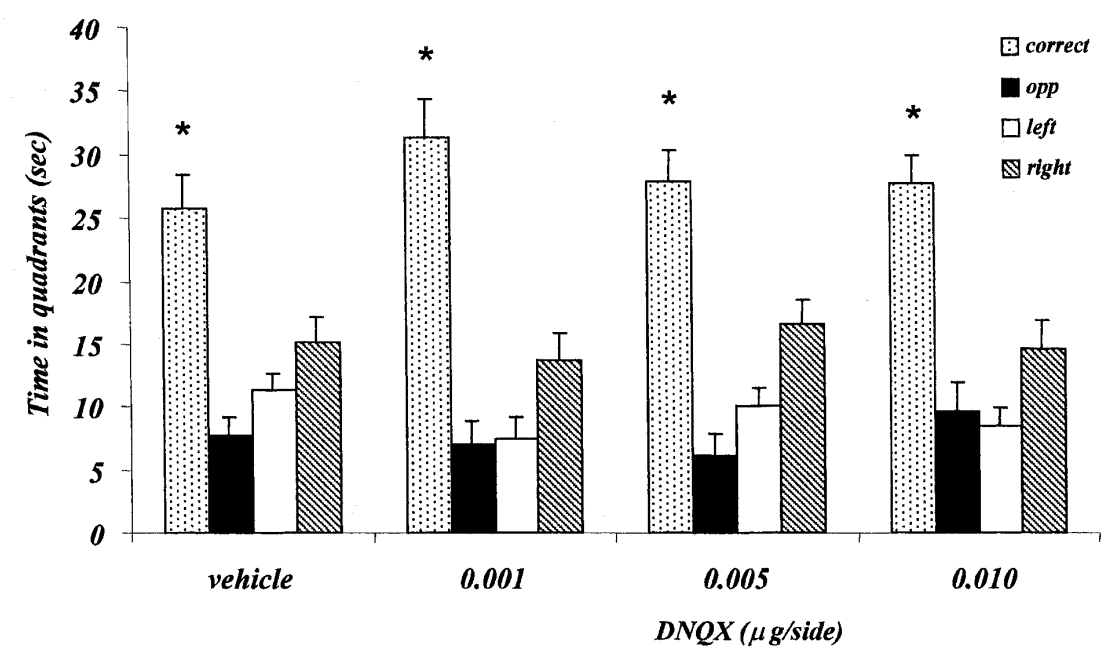

B

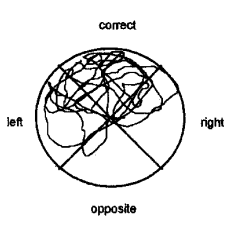

Vehicle

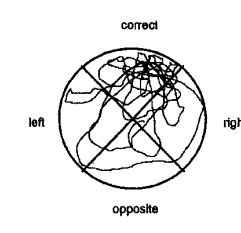

$D N Q X 0.001$

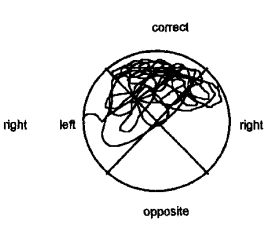

$D N Q X 0.005$

Figure 5 Experiment 2, effect of posttraining vehicle and DNQX administrations on probe test performance in the place water-maze task. (A) Time spent in the four quadrants by vehicle, 0.001 $\mu \mathrm{g} / \mathrm{side}$ DNQX, $0.005 \mu \mathrm{g} / \mathrm{side}$ DNQX, and $0.010 \mu \mathrm{g} / \mathrm{side}$ DNQX. (B) Representative paths taken by animals treated with vehicle, $0.001 \mu \mathrm{g} /$ side DNQX, $0.005 \mu \mathrm{g} / \mathrm{side}$ DNQX, and $0.010 \mu \mathrm{g} / \mathrm{side}$ DNQX. $\left(^{*}\right) p<0.05$, correct versus opposite, right, left quadrants within groups.

or a single proximal cue to approach the platform, and that the information processed could be stored during a 24-h delay.

In this study, we investigated the role of Nacc in the consolidation of different types of information through the blockade of NMDA and AMPA receptors within this structure immediately after the training phase. Posttraining NMDA receptor blockade dose-dependently reduced the time spent in the correct quadrant as well as the index during the probe test in the place water maze task $24 \mathrm{~h}$ later. These results demonstrate that NMDA receptors within the Nacc are involved in the consolidation of spatial information. In view of the temporary effect of the treatment and the long delay between training and test, it is unlikely that the drug affected task performance during the probe test. Moreover, in a recent experiment we have shown that immediate posttraining AP-5 injections into the Nacc impair performance on a spatial learning task $24 \mathrm{~h}$ later, but focal administrations 120 min after training have no effects (Roullet et al. 2001), thus excluding possible proactive drug effects $24 \mathrm{~h}$ after AP-5 administration. Furthermore, no changes in swimming speed or differences in time spent in the periphery of the pool were observed between groups on the probe test day. This indicates that the deficits provoked by AP-5 administrations on probe test performance are not attributable to a general motor impairment or a thigmotactic behavior. The representative paths taken by animals treated with saline or AP-5 (Fig. 3B) seem to confirm the hypothesis of a selective impairment of spatial memory consolidation. Control animals actively searched the platform in the quadrant where it was located during training phase. Animals injected with the lower dose of AP-5 $(0.10 \mu \mathrm{g} /$ side $)$ extended their research to the adjacent quad-

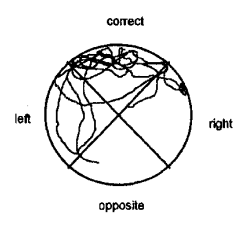

$D N Q X 0.010$ rant, and mice injected with the higher dose tended to swim all over the pool. This indicates that NMDA receptor blockade selectively affected consolidation of spatial information, which is necessary to locate the exact position of the platform.

Posttraining injections of different doses of AMPA antagonist, on the contrary, induced no effect on the place version of the water maze. Both vehicle- and DNQXinjected mice spent significantly more time in the correct quadrant during the probe test and actively searched for the platform where it had been previously located (Fig. $5 B)$. This indicates that DNQX did not affect consolidation of spatial information. It has been previously demonstrated that AMPA receptors are not involved in memory consolidation (Liang et al. 1994; Riedel et al. 1999; Roullet et al. 2001), although an increased binding of AMPA receptors has been found in the hippocampus $3 \mathrm{~h}$ after spatial learning (Izquierdo and Medina 1997). Moreover, a pretraining increase of AMPA-mediated synaptic activity induced an improvement of performance $24 \mathrm{~h}$ later in different learning tasks (Staubli et al. 1994). It is therefore possible that AMPA receptors could modulate memory retention acting on the first steps of learning processes or in a later phase of memory formation. In a recent study, we demonstrated that focal DNQX injections within the Nacc immediately or $120 \mathrm{~min}$ after training did not affect performance $24 \mathrm{~h}$ later, in a spatial learning task designed to estimate the ability of mice to match objects with their previous position (Roullet et al. 2001). The present results confirm previous observations, demonstrating that AMPA receptors within the Nacc are not involved in spatial memory consolidation in the water-maze task.

In the cue water maze, both posttraining NMDA and AMPA receptor blockades did not impair mice performance $24 \mathrm{~h}$ later. Vehicle- as well as drug-injected mice focused their search of the platform in the quadrant where the visual cue was suspended (Fig. 7B), thus all three groups were able to use the proximal cue to find the platform. This indicates that posttraining AP-5 and DNQX injections did not induce a general attentional, motoric, or motivational deficit, thus confirming a selective impairment on spatial memory consolidation induced by NMDA receptor blockades within this structure, as shown in the first experiment. These findings are consistent with recent results of Setlow and McGaugh (1998), who showed that focal sulpiride injections within the Nacc impair memory consolidation in a spatial watermaze task, while sparing consolidation of visual information in the classical nonspatial version. In the cue versions used in the present study, animals are not allowed to see the platform directly, but they can approach it using a single proximal cue. It is assumed that the presence of a salient cue allows the development of a guidance strategy based on the association between the cue and the goal and that it does not require spatial memory per se (Brandner and Schenk 1998). Therefore, the results of this experiment indicate that glutamate receptors located within the Nacc are not involved in consolidating the information necessary to perform a cue-guided response. This is interesting also in light of the involvement of this structure in learning processes 


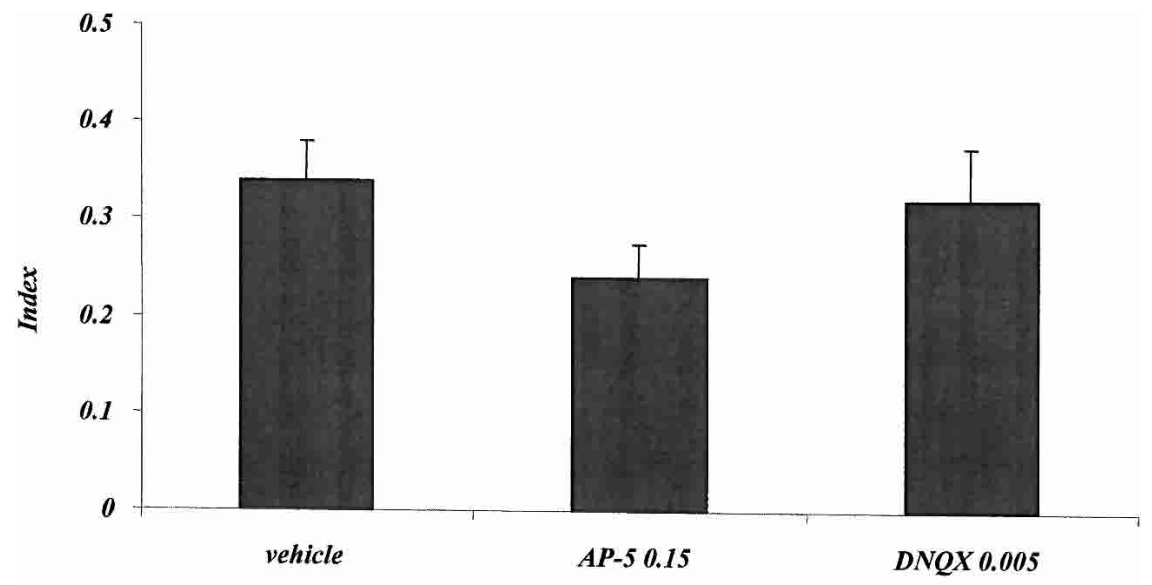

$(\mu \mathrm{g} / \mathrm{side})$

Figure 6 Experiment 3, effect of posttraining vehicle, AP-5, and DNQX administrations on the cue water-maze task. The histogram represents the index \pm SEM, calculated as the difference between the number of crossings of the annulus surrounding the expected position of the platform and the mean number of crossings of the three remaining annuli, divided by the total number of annulus crossings, during the probe test.

based on stimulus-reward association (Robbins and Everitt 1996).

Several authors have previously indicated an important role of Nacc in learning and memory processes (Annett et al. 1989; Maldonado-Irizarry and Kelley 1995; Usiello et al. 1998). However, most of these studies used pretraining pharmacological or lesion treatments that do not allow distinguishing between the different phases of learning and memory. On the contrary, very few studies investigated the involvement of this structure in the different steps of information processing (Lorenzini et al. 1995; Setlow and McGaugh 1998, 1999a; Roullet et al. 2001). In the present work, we performed posttraining pharmacological manipulations, which are thought to selectively act on memory consolidation (McGaugh 1966; Gold and McGaugh 1975). In addition, we used a modified version of the Morris water-maze task, in which all training sessions are performed during the same day. Compared to the classical distributed procedure, the utilization of a massed training procedure has different theoretical and technical advantages. For example, to study the involvement of a structure in learning and memory, authors generally performed multiple drug injections during several days: this can be avoided with the present procedure. Furthermore, it has been demonstrated that memory could be reactivated and reconsolidated several times in a distributed procedure (Nader et al. 2000; Sara 2000). In this case, it is therefore difficult to dissociate the effects of a drug on the first memory consolidation from those involved in the reconsolidation and stabilization of the memory trace (Roullet and Sara 1998; Przybyslawski et al. 1999). The massedtraining procedure used in this study lasts for less than $80 \mathrm{~min}$ and allows a single drug injection. This excludes possible misunderstandings of which phase of memory formation the Nacc is involved in.

Learning in the spatial water maze has been suggested to depend on two major circuits, including the hippocampus and the dorsal striatum (O'Keefe and Nadel 1978; De Bruin et al. 2001), which control different components of maze performance: the first circuit acts on spatial information processing and the second on the procedural component of the task, such as "swimming away from the walls of the maze" (Bannerman et al. 1995; Setlow and McGaugh 1999a). According to this view, several authors demonstrated that lesions or temporary inactivation of the hippocampus induced a selective impairment on the ability of the animals to locate the platform using spatial cues (Riedel et al. 1999; Lassalle et al. 2000). On the contrary, pretraining or posttraining manipulations of dorso-medial and posteroventral caudate-putamen affected different procedural components of the water maze, increasing, for example, time spent in the periphery of the pool (Devan et al. 1999; Setlow and McGaugh 1999b). In the present study, pharmacological manipulations of the Nacc selectively affected spatial memory consolidation without altering procedural or motor parameters (swimming speed, time spent in periphery of the pool). This seems to indicate that the impairment induced by NMDA receptors blockade within the Nacc has more similarities with the hippocampal deficit. However, the involvement of the Nacc in the two different strategies (place vs. procedural) has not been elucidated, and further studies will be needed to clarify the functional role played by this structure in allocortical-striatal circuits.

\section{MATERIALS AND METHODS}

\section{Animals}

A total of 137 CD1 male mice (IFFA CREDO, Lyon, France) were used in the present study. Upon arrival, animals were housed in groups of five in standard breeding cages $(21 \times 21 \times 12 \mathrm{~cm})$ placed in a rearing room at a constant temperature $\left(22^{\circ} \pm 1^{\circ} \mathrm{C}\right)$ under diurnal conditions (light-dark: 08:00-20:00), with food and water ad libitum. At the time of surgery, they were $~ 9-10$ weeks old and their weights ranged from 35-40 g. All experiments were run in the afternoon, between 14:00 and 18:00.

Every possible effort was made to minimize animal suffering, and all procedures were in strict accordance with European Community regulations on the use of animals in research and NIH guidelines on animal care.

\section{Surgery}

Mice underwent surgery 1 wk after their arrival. They were anesthetized with chloral hydrate $(400 \mathrm{mg} / \mathrm{kg})$ and placed in a stereotaxic frame (David Kopf Instruments) with a mouse adapter and lateral bars. After placing the animals on the stereotaxic apparatus, the head skin was cut longitudinally and bilateral guide cannulae $(0.5 \mathrm{~mm}$ in diameter) were fixed on the calvarium with dental acrylic. The following coordinates with lambda and bregma in the same horizontal plane were used: anterior to bregma, $+1.7 \mathrm{~mm}$; lateral to midline, $\pm 1 \mathrm{~mm}$; ventral from the dura, $-2.2 \mathrm{~mm}$, according to Franklin and Paxinos (1997). Mice were then left in their home cages for a recovery period of $1 \mathrm{wk}$.

\section{Apparatus}

The circular swimming pool $(110 \mathrm{~cm}$ in diameter and $30 \mathrm{~cm}$ in height) was made of ivory-colored PVC, filled with water $\left(25^{\circ} \pm 1^{\circ} \mathrm{C}\right)$ made opaque with Lytron 631 , to $15 \mathrm{~cm}$ below the edge of the wall. Four start positions (labeled N, S, E, and W) were located equidistantly around the edge of the maze, dividing it into four equal quadrants. During training, a circular goal platform painted white $(9 \mathrm{~cm}$ diameter) was laid in the center of each quadrant, $15 \mathrm{~cm}$ from the wall. The platform had a rough (metal grid) surface, providing a sufficient grip for the animals to climb on top of it. The apparatus was placed in a separate room and surrounded by white curtains containing several extramaze cues, according to the procedure used. It was illuminated by a white 
A

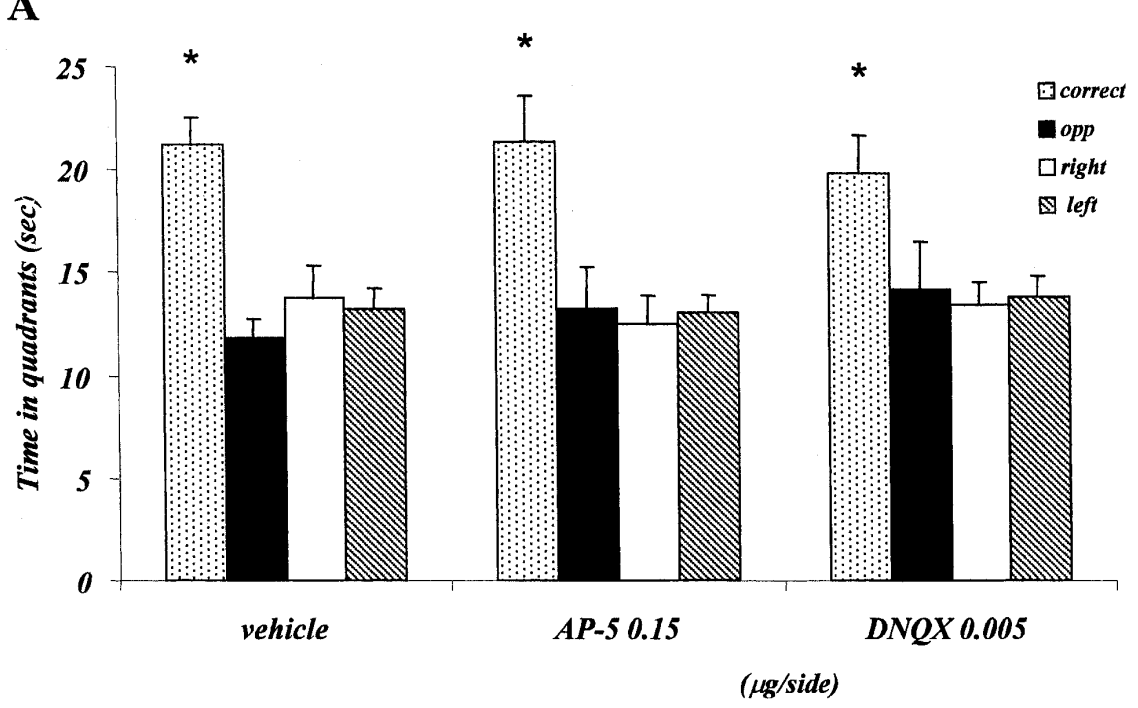

B
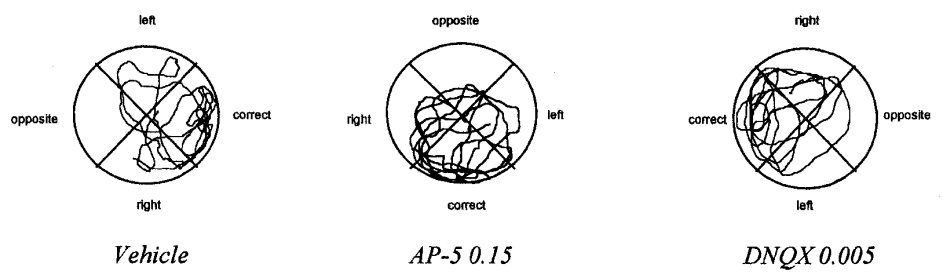

Figure 7 Experiment 3, effect of posttraining vehicle, AP-5, and DNQX administrations on probe test performance in the place water-maze task. $(A)$ Time spent in the four quadrants by mice injected with saline, $0.15 \mu \mathrm{g} /$ side AP-5, and $0.005 \mu \mathrm{g} /$ side DNQX. (B) Representative paths taken by animals treated with vehicle, $0.15 \mu \mathrm{g} /$ side AP-5, and $0.005 \mu \mathrm{g} /$ side DNQX. $\left(^{*}\right) p<0.05$, correct versus opposite, right, left quadrants within groups.

light $(60 \mathrm{~W})$ and surmounted by a videocamera connected to a videorecorder and a monitor.

\section{Procedure}

The general procedure consisted of three different phases: a familiarization phase, a training phase, and a probe test.

On the first day, mice were individually submitted to a single familiarization session of three trials, with the platform located always in the same quadrant and protruding $0.5 \mathrm{~cm}$ over the surface of the water. The session started with the mouse standing on the platform for $60 \mathrm{sec}$. At the beginning of each trial, mice were introduced in the maze facing the wall at one of the four designated starting points $(\mathrm{N}, \mathrm{S}, \mathrm{E}, \mathrm{W})$, and allowed to swim freely or until they reached the platform. Mice failing to find the platform within a fixed period of $60 \mathrm{sec}$ were gently guided by hand to the platform, and a maximum escape latency of $60 \mathrm{sec}$ was recorded. After the animals climbed to the platform, they were allowed to remain on it for an additional $60 \mathrm{sec}$, and were subsequently replaced in the maze from a different starting position. The starting positions were determined in a pseudorandom order, such that each of them was used once in a single session.

Training started the next day. Mice were submitted to four consecutive sessions of three trials, with an intersession delay of 15-20 min during which they were returned to their home cages. The procedure was the same as in the familiarization phase, except for the platform, which was submerged $0.5 \mathrm{~cm}$ beneath the surface of the water. Animals were introduced in the maze from different starting points and allowed to swim freely or until they reached the platform. Mice failing to find the platform within a fixed period of $60 \mathrm{sec}$ were gently guided by hand to the platform, and a maximum escape latency of $60 \mathrm{sec}$ was recorded. The starting positions were determined in a pseudorandom order, and the sequence of starting locations was randomized such that each of them was used three times during the four training sessions.

Then, $24 \mathrm{~h}$ after the last training session, the mice were submitted to a single trial of the probe test. The platform was removed, and mice, starting from the center of the pool, were allowed a 60 -sec search for the platform.

Two different versions of the water maze have been used. In the place version, several extramaze visual cues, $\sim 50-100 \mathrm{~cm}$ away from the pool, were attached to the walls surrounding the apparatus. Mice were required to navigate to the invisible platform using the spatial cues available in the room. The platform was located always in the same quadrant during both familiarization and training phases. In the cue version, all the distal visual cues were removed, and a single proximal cue was present, a black-painted plastic ball $(3 \mathrm{~cm}$ diameter) hanging $7 \mathrm{~cm}$ above the surface of the platform. The position of the platform and the ball changed across sessions, to prevent animals from using spatial bias. During the probe test, the platform was removed, and the ball was located in the quadrant opposite to that used in the last training session.

Selective and reversible NMDA and AMPA receptor blockades were obtained through direct infusions into the Nacc of (-)-AP-5 (AP-5) and DNQX, competitive antagonists of the NMDA and the AMPA receptors, respectively. AP-5 was dissolved in saline solution $(0.9 \% \mathrm{NaCl}$ in distilled water), and DNQX was dissolved in a solution of $2 \%$ DMSO in distilled water. Mice were assigned to drug treatment groups and given injections immediately following the last training trial. They were tested for retention $24 \mathrm{~h}$ later. Both AP-5 (0.1 and $0.15 \mu \mathrm{g} / \mathrm{side}$ ) and DNQX $(0.001,0.005$, and $0.010 \mu \mathrm{g} / \mathrm{side})$ were focally injected into the Nacc in a volume of $0.2 \mu \mathrm{L}$. The rationale for using these doses was based on previous studies and preliminary experiments in which they were demonstrated to be effective in impairing spatial learning, when focally administered in the Nacc (Sargolini et al. 1999; Roullet et al. 2001). Drug-treated animals were always compared with control mice injected with the same volume of vehicle solution, under the same conditions.

\section{Data Collection and Statistics}

Data collection was performed using videorecordings; the observer was always blind to treatment. Several parameters of behavioral performance were recorded. During training sessions, latency to mount onto the platform was recorded in each trial. During the probe test, two main measures have been scored: (1) the time spent in each quadrant of the pool; (2) the number of annulus crossings, that is, the number of times a mouse crossed an ideal circle (14 cm diameter) located around each of the four possible platform positions in the four quadrants. We used these basic measures to calculate an index, as the difference between the number of crossings of the annulus surrounding the expected position of the platform and the mean number of crossings of the three remaining annuli, divided by the total number of annulus crossings. Additionally, the movements of the animals during the probe test were recorded using a computerized detection system. The position of the animal was determined 5 times per second and recorded as $x$ and $y$ coordinates in time. Subsequently, these data have been used to calculate the average swimming speed and the time spent in the periphery of the pool, 
situated at $10 \mathrm{~cm}$ from the wall, according to Setlow and McGaugh (1999a).

The SYSTAT 9.0 statistical software package was used for data analysis. For the training phase, trial latencies were added for each session (three trials per session), and the session data were analyzed with a repeated measure ANOVA analysis (between factor: treatment, 3 or 4 levels; within factor: sessions, 4 levels). The time spent in each of the four quadrants during the probe test was analyzed using a two-factor ANOVA design (first factor: treatment, 3 or 4 levels; second factor: quadrants, 4 levels). Finally a one-factor (treatment: 3 or 4 levels) ANOVA design was used to analyze possible differences in index, swimming speed, and time spent in the periphery of the pool, during the probe test. Post hoc multiple comparisons were carried out when allowed, using Tukey's Honestly Significant Distance (HSD) test.

\section{Histology}

At the completion of the experiment, mice were killed by an overdose of chloral hydrate, and the brains were removed and frozen at $-20^{\circ} \mathrm{C}$. Cannula placements were determined by examination of serial coronal sections $(25 \mu \mathrm{m})$ stained with Cresyl Violet. Only animals showing correct Nacc placements were included in the statistical analysis.

\section{ACKNOWLEDGMENTS}

This study has been partially supported by a fellowship of "Fondation pour la Recherche Medicale" to F.S. and MURST grant 2000 and 2001 to A.O.

The publication costs of this article were defrayed in part by payment of page charges. This article must therefore be hereby marked "advertisement" in accordance with 18 USC section 1734 solely to indicate this fact.

\section{REFERENCES}

Albin, R.L., Makowiec, R.L., Hollingsworth, Z., Dure, I.V.L.S., Penney, J.B., and Young, A.B. 1991. Excitatory amino acid binding sites in the basal ganglia of the rat: A quantitative autoradiographic study. Neuroscience 46: 35-48.

Annett, L.E., McGregor, A., and Robbins, T.W. 1989. The effects of ibotenic acid lesions of the nucleus accumbens on spatial learning and extinction in the rat. Behav. Brain Res. 31: 231-242.

Bannerman, D.M., Good, M.A., Butcher, S.P., Ramsay, M., and Morris, R.G. 1995. Distinct components of spatial learning revealed by prior training and NMDA receptor blockade. Nature 378: 182-186.

Brandner, C. and Schenk, F. 1998. Septal lesions impair the acquisition of a cued place navigation task: Attentional or memory deficit? Neurobiol. Learn. Mem. 69: 106-125.

De Bruin, J.P.C., Moita, M.P., Brabander, H.M., and Joosten, R.N.J.M. 2001. Place and response learning of rats in a Morris water maze: Differential effects of fimbria fornix and medial prefrontal cortex lesions. Neurobiol. Learn. Mem. 75: 164-178.

Devan, B.D., McDonald, R.J., and White, N.M. 1999. Effects of medial and lateral caudate-putamen lesions on place- and cue-guided behaviours in the water maze: Relation to thigmotaxis. Behav. Brain Res. 100: $5-14$

Floresco, S.B., Seamans, J.K., and Phillips, A.G. 1997. Selective role of hippocampal, prefrontal cortical, ventral striatal circuits in radial arm maze tasks with or without a delay. J. Neurosci. 17: 1880-1890.

Franklin, B.J. and Paxinos, G. 1997. The mouse brain in stereotaxic coordinates. Academic Press, San Diego, CA.

Gold, P.E. and McGaugh, J.L. 1975. A single trace, two process view of memory process. In Short-term memory (eds. D. Deutsch and J.A. Deutsch), pp. 355-378. Academic Press, New York.

Groenewegen, H.J., Vermeulen-van Der Zee, E., Te Kortschot, A., and Witter, M.P. 1987. Organization of the projections from the subiculum to the ventral striatum in the rat. A study using anterograde transport of Phaseolus vulgaris leucoagglutinin. Neuroscience 23: 103-120.

Izquierdo, I. and Medina, J.H. 1997. Memory formation: The sequence of biochemical events in the hippocampus and its connection to activity in other brain structures. Neurobiol. Learn. Mem. 68: $285-316$
Kelley, A.E. and Domesick, V.B. 1982. The distribution of the projections from the hippocampal formation to the nucleus accumbens in the rat: An anterograde- and retrograde-horseradish peroxidase study. Neuroscience 7: 2321-2335.

Lassalle, J.M., Battaille, T., and Halley, H. 2000. Reversible inactivation of the hippocampal mossy fiber synapses in mice impairs spatial learning, but neither consolidation nor memory retrieval, in the Morris navigation task. Neurobiol. Learn. Mem. 73: 243-257.

Liang, K.C., Hon, W., Tyan, Y.M., and Liao, W.L. 1994. Involvement of hippocampal NMDA and AMPA receptors in acquisition, formation and retrieval of spatial memory in the Morris water maze. Chin. J. Physiol. 37: 201-212.

Lipp, H.P. and Wolfer, D.P. 1998. Genetically modified mice and cognition. Curr. Opin. Neurobiol. 8: 272-280.

Lorenzini, C.A., Baldi, E., Bucherelli, C., and Tassoni, G. 1995. Time-dependent deficits of rat's memory consolidation induced by tetrodotoxin injections into the caudate-putamen, nucleus accumbens, and globus pallidus. Neurobiol. Learn. Mem. 63: 87-93.

Maldonado-Irizarry, C.S. and Kelley, A.E. 1995. Excitatory amino acid receptors within nucleus accumbens subregions differentially mediate spatial learning in the rat. Behav. Pharmacol. 6: 527-539.

McGaugh, J.L. 1966. Time-dependent process in memory storage. Science 153: $1351-1358$.

Morris, R. 1984. Development of a water maze procedure for studying spatial learning in the rat. J. Neurosci. Methods 11: 47-60.

Nader, K., Schafe, G.E., and Le Doux, J.E. 2000. The labile nature of consolidation theory. Nature 1: 216-219.

O'Keefe, J. and Nadel, L. 1978. The hippocampus as a cognitive map. Clarendon Press, Oxford, UK.

Ploeger, G.E., Spruijt, B.M., and Cools, A.R. 1994. Spatial localization is affected by intra-accumbens injections of the dopaminergic antagonist Haloperidol. Behav. Neurosci. 108: 927-934.

Przybyslawski, J., Roullet, P., and Sara, S.J. 1999. Attenuation of emotional and non emotional memories after their reactivation: Role of $\beta$ adrenergic receptors. J. Neurosci. 19: 6623-6628.

Riedel, G., Micheau, J., Lam, A.G.M., Roloff, E.V.L., Martin, S.J., Bridge, H., de Hoz, L., Poeschel, B., McCulloch, J., and Morris, R.G. 1999. Reversible neural inactivation reveals hippocampal participation in several memory processes. Nat. Neurosci. 2: 898-905.

Robbins, T.W. and Everitt, B.J. 1996. Neurobehavioural mechanisms of reward and motivation. Curr. Opin. Neurobiol. 6: 228-236.

Roullet, P. and Sara, S. 1998. Consolidation of memory after its reactivation: Involvement of $\beta$ noradrenergic receptors in the late phase. Neural. Plast. 6: 63-68.

Roullet, P., Sargolini, F., Oliverio, A., and Mele, A. 2001. NMDA and AMPA antagonist infusions into the ventral striatum impair different steps of spatial information processing in a nonassociative spatial task in mice. J. Neurosci. 21: 2143-2149.

Sara, S.J. 2000. Retrieval and reconsolidation: Toward a neurobiology of remembering. Learn. Mem. 7: 73-84.

Sargolini, F., Roullet, P., Oliverio, A., and Mele, A. 1999. Effects of lesions to the glutamatergic afferents to the nucleus accumbens in the modulation of reactivity to spatial and non-spatial novelty in mice. Neuroscience 93: 855-867.

Schacter, G.B., Yang, C.R., Innis, N.K., and Mogenson, G.J. 1989. The role of hippocampus-nucleus accumbens pathway in radial-arm maze performance. Brain Res. 494: 339-349.

Seamans, J.K. and Phillips, A.G. 1994. Selective memory impairments produced by transient lidocaine-induced lesions of the nucleus accumbens in rats. Behav. Neurosci. 108: 456-468.

Setlow, B. and McGaugh, J.L. 1998. Sulpiride infused into the nucleus accumbens impairs memory for spatial water maze training. Behav. Neurosci. 112: 603-610.

. 1999a. Differential effects of immediate posttraining sulpiride microinfusions into the nucleus accumbens shell and core on Morris water maze retention. Psychobiol. 27: 248-255.

- 1999b. Involvement of the posteroventral caudate-putamen in memory consolidation in the Morris water maze. Neurobiol. Learn. Mem. 71: 240-247.

Staubli, U., Rogers, G., and Lynch, G. 1994. Facilitation of glutamate receptors enhances memory. Proc. Natl. Acad. Sci. 91: 777-781.

Usiello, A., Sargolini, F., Roullet, P., Ammassari-Teule, M., Passino, E., Oliverio, A., and Mele A. 1998. N-Methyl-D-aspartate receptors in the nucleus accumbens are involved in detection of spatial novelty in mice. Psychopharmacology 137: 175-183.

Received July 19, 2002; accepted in revised form April 17, 2003. 


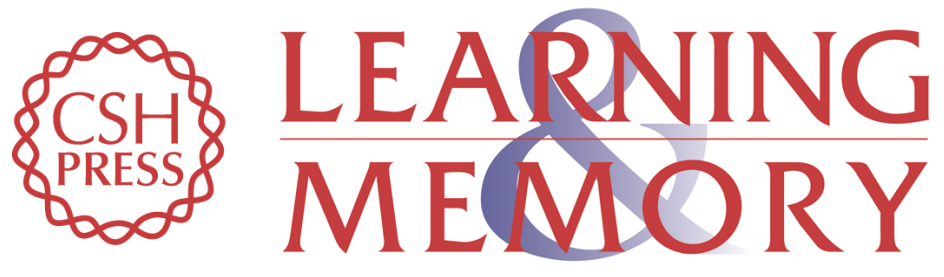

\section{Differential Involvement of NMDA and AMPA Receptors Within the Nucleus Accumbens in Consolidation of Information Necessary for Place Navigation and Guidance Strategy of Mice}

Francesca Sargolini, Cédrick Florian, Alberto Oliverio, et al.

Learn. Mem. 2003, 10:

Access the most recent version at doi:10.1101//m.54003

References This article cites 31 articles, 6 of which can be accessed free at: http://learnmem.cshlp.org/content/10/4/285.full.html\#ref-list-1

License

Email Alerting

Receive free email alerts when new articles cite this article - sign up in the box at the Service top right corner of the article or click here. 